\title{
Genetic differences in follicular thyroid carcinoma between Asian and Western countries: a systematic review
}

\author{
Toru Odate ${ }^{1}$, Naoki Oishi ${ }^{1}$, Huy Gia Vuong ${ }^{2}$, Kunio Mochizuki $^{1}$, Tetsuo Kondo ${ }^{1}$ \\ ${ }^{1}$ Department of Pathology, University of Yamanashi, Chuo, Yamanashi, Japan; ${ }^{2}$ Department of Pathology, Oklahoma University Health Sciences \\ Center, Oklahoma City, OK, USA \\ Contributions: (I) Conception and design: T Odate; (II) Administrative support: T Odate, N Oishi, K Mochizuki, T Kondo; (III) Provision of study \\ materials or patients: T Odate, HG Vuong; (IV) Collection and assembly of data: T Odate, HG Vuong; (V) Data analysis and interpretation: All \\ authors; (VI) Manuscript writing: All authors; (VII) Final approval of manuscript: All authors. \\ Correspondence to: Tetsuo Kondo, MD, PhD. Department of Pathology, University of Yamanashi, 1110 Shimokato, Chuo, Yamanashi 409-3898, Japan. \\ Email: ktetsuo@yamanashi.ac.jp.
}

\begin{abstract}
Thyroid cancer is the most common endocrine malignancy, and follicular thyroid carcinoma (FTC) is the second most common thyroid cancer following papillary thyroid carcinoma (PTC). RAS mutation and PAX8/PPAR $\gamma$ rearrangement are the two representative genetic alterations in FTC, and there are studies from various countries on their regional frequencies. In this study, we systematically reviewed all available literature aiming to create a complete global map showing the frequencies of these common oncogenic drivers in FTC and to highlight the trends in Asian and Western countries. We performed a search in two electronic databases and identified 71 studies that fit our criteria from 1,329 studies found with our database search terms. There were 54 articles with 1,143 FTC patients and 39 articles with 764 FTC patients available for calculating the frequency of $R A S$ mutation and PAX8/PPAR $\gamma$ rearrangement, respectively. NRAS mutation was the most frequent $R A S$ mutation in all regions, followed by $H R A S$ and KRAS mutation. The frequency of RAS mutation in Asian countries was higher than Western countries (34\% vs. $27 \%, \mathrm{P}=0.006$ ) when the mutation detection method was not taken into account. In contrast, this difference in RAS mutation incidence between Asian and Western countries ( $28 \%$ s. $25 \%, \mathrm{P}=0.47)$ did not show up in our subgroup analysis incorporating only studies using direct sequencing method. The reported difference of $R A S$ mutation frequency in the previous literature might not be due to the true prevalence of $R A S$ mutation. They could be attributed to the difference in the detection method. As to PAX8/PPAR rearrangement, Western countries overall had a much higher prevalence than Asian countries (23\% vs. 4\%, $\mathrm{P}<0.001$ ), but some European countries had a low incidence, implying regional heterogeneity of PAX8/ $P P A R \gamma$ rearrangement. A substantial lack of mutation data in FTC was found in several regions of the world such as Central Asia, Middle East, Africa, and Central and South America. Our results provide the most comprehensive global status of representative genetic alterations in FTC and highlight the similarities and differences between Asian and Western countries.
\end{abstract}

Keywords: Follicular thyroid carcinoma (FTC); PAX8/PPAR $\gamma$; RAS; systematic review

Submitted Mar 16, 2020. Accepted for publication Jun 22, 2020.

doi: $10.21037 / g s-20-356$

View this article at: http://dx.doi.org/10.21037/gs-20-356 


\section{Introduction}

Thyroid cancer is the most common endocrine malignancy with 567,000 new cases and 41,000 deaths worldwide in 2018 (1). Thyroid cancer generally derives from follicular epithelial cells. Follicular thyroid carcinoma (FTC) is the second most common thyroid cancer originating from thyroid epithelial cells following papillary thyroid carcinoma (PTC) (2).

$B R A F$ mutation is the most common genetic alteration in PTC, accounting for approximately $60 \%$ of the alterations (3). In contrast, $R A S$ mutation is the most prevalent oncogenic drivers in FTC (4), although recent studies using next generation sequencing (NGS) revealed novel driver mutations other than $R A S$ such as DICER1, EIF1AX, and EZH1 (5). RAS mutation is also associated with poor prognosis in FTC. Several studies indicated that $R A S$-mutated FTCs were associated with poor overall survival and distant metastasis $(6,7)$. The incidence of $R A S$ mutation in FTC varies among studies ranging from 10.5\% to $56.9 \%$, which is higher than follicular adenoma (FA) from $8 \%$ to $48 \%(8,9)$. Some of this variation is due to the relatively small number of samples available for the studies and the use of different methodologies (9). Moreover, some researchers tried to explain the geographical difference in the incidence of $R A S$ mutation in terms of iodine intake of the populations. The results remain controversial $(10,11)$.

Some oncogenic genetic rearrangements also contribute to tumorigenesis in follicular thyroid neoplasms, and PAX8/ $P P A R \gamma$ rearrangement is the most common in FTC and FA at about $30 \%$ and $10 \%$ occurrence (12). This gene rearrangement results in the production of the PAX8/ PPAR $\gamma$ fusion protein which acts as an oncoprotein by inhibiting endogenous PPAR $\gamma$ activity, although the mechanisms of tumorigenesis induced by this fusion gene are not fully understood (13). Other chromosomal rearrangements including DERL-COX6C and CREB3L2$P P A R \gamma$ make up only a subset of FTCs (14). Recent large cohort studies suggested that $P A X 8 / P P A R \gamma$ did not correlate with invasiveness or affect prognosis in FTC (15). Geographical differences in the incidence of PAX8/ $P P A R \gamma$ rearrangement in FTC is better recognized than $R A S$ mutation in FTC. Interestingly, $P A X 8 / P P A R \gamma$ rearrangement is considered to be much more common in Western countries than in Asia. This may be attributed to ethnic differences, iodine intake, or radiation exposure, but there is no definitive conclusion (16-18).

The genetic alterations in thyroid cancer have received attention as possible diagnostic or treatment targets (4). However, when adopting therapeutic or diagnostic strategies based on molecular information, there should be careful consideration of the various genetic backgrounds of different populations, especially in Asian and Western countries. Although there are studies on the frequency of $R A S$ mutation and $P A X 8 / P P A R \gamma$ rearrangement in FTC from various regions, worldwide comprehensive information is still limited. Grasping world trends of genetic backgrounds in FTC is important for the sake of clinical practice. Therefore, we systematically reviewed the available literature on the subject with the goal of creating a global mutational map of FTC. We present the following article in accordance with the PRISMA reporting checklist (available at http://dx.doi.org/10.21037/gs-20-356).

\section{Methods}

\section{Literature search}

We searched the electronic databases of PubMed, Web of Science for relevant English papers from the inception in 1987 to September 2019 using the following search terms: (follicular OR follicular thyroid) AND (carcinoma OR cancer OR tumor) AND (RAS OR NRAS OR HRAS OR KRAS OR PAX8 OR PPAR $\gamma$ ). Additionally, we performed a manual search by reviewing the citations within the included publications and reviews. Our study protocol generally followed the recommendation of the Preferred Reporting Items for Systematic Review and Meta-analysis (PRISMA) statement (19).

\section{Selection criteria and abstract screening}

We imported all search results from each electronic database into EndNote (Clarivate Analytics, PA, USA) and deleted duplicates. Two reviewers independently screened titles and abstracts of included studies (TO and HGV). We only included studies in the final analysis that contained information on the frequency of any of the RAS mutations or the PAX8/PPAR $\gamma$ fusion gene in FTC. We did not include the studies dealing with only borderline tumors introduced by recent WHO classification such as non-invasive follicular thyroid neoplasm with papillary-like nuclear features (NIFTP), follicular tumor of uncertain malignant potential (FT-UMP), and well-differentiated tumor of uncertain malignant potential (WDT-UMP) (20). The exclusion criteria were (I) studies on thyroid tumors other than FTC 


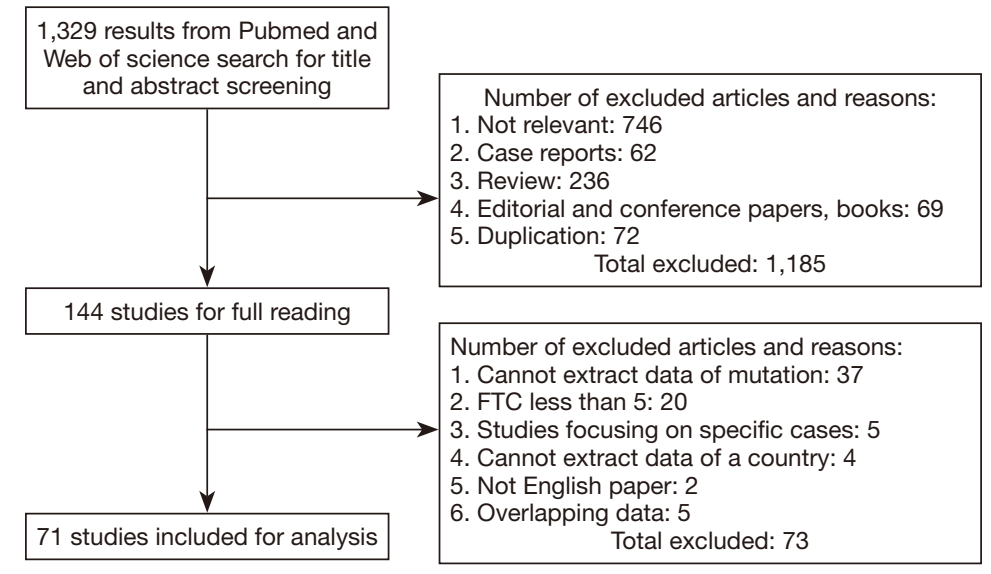

Figure 1 Study flowchart.

including Hurthle cell carcinoma which was previously considered an oncocytic variant of FTC; and (II) case reports, reviews, editorial papers, conference and meeting abstracts, or books. The 2 reviewers resolved any discrepancies between them through discussion and consensus.

\section{Full-text screening}

Subsequently, the reviewers read the full text of all potential articles and excluded many from our study. After completing the selection of articles, we extracted the data into a standardized extraction form. Any disagreements were solved, again, by discussion and consensus. The data extracted from the studies included information about the institutions, country, year of publication, admission period of the study, mutation detecting methods, type of samples, study design, age, gender, and frequency of genetic alterations. Extracted genetic alterations were exon 1 or exon 2 mutation of each $R A S$ gene and PAX8/PPAR $\gamma$ rearrangement.

\section{Data analysis}

Statistical analyses were conducted using the GraphPad Prism 8 software (GraphPad software, San Diego California, USA). Categorical variables were compared using the Pearson chi-square test. A P value $<0.05$ was considered statistically significant.

\section{Results}

We found 1,329 articles through title and abstract screening and selected 144 of them for full-text reading. After reading these articles' full texts, we excluded 73 studies for the following reasons: (I) inability to extract frequency data of genetic alterations, (II) number of FTC samples in the study was less than 5 FTCs and inadequate for estimating frequency, (III) the study focused on specific FTCs such as radiation induced or FTCs with distant metastases, (IV) no information as to country of samples, (V) not an English language paper, and (VI) overlapping data between the studies. We used the remaining 71 studies that included data of at least one genetic alteration in our final analysis (Figure 1). The characteristics of all included studies are listed in Table 1.

\section{RAS mutation frequency in FTC patients by geographic region}

There were 54 articles with a combined 1,143 FTC patients available for calculating the frequency of $R A S$ mutation. These included 19 studies from Asia $(5,6,10,21-34,36,37)$, 21 studies from Europe (11,39-41,43,46-53,55-60,63,65), 12 studies from North America (11,67-77), 1 study from Oceania (83) and 1 study from the Middle East (38). We extracted the data on each $R A S$ mutation, including NRAS, $H R A S$ and $K R A S$, from these articles and then calculated the frequency of FTC patients who had a $R A S$ mutation. Table 2 and Figure $2 A$ show the worldwide frequency of $R A S$ mutation. NRAS mutation is the most frequent in all regions, followed by $H R A S$ and KRAS mutation.

Most of the Asian countries had a greater than $30 \%$ prevalence of $R A S$ mutation, while some European countries such as Germany (8\%), Portugal (12\%) and Turkey (0\%) 
Table 1 Characteristics of included studies

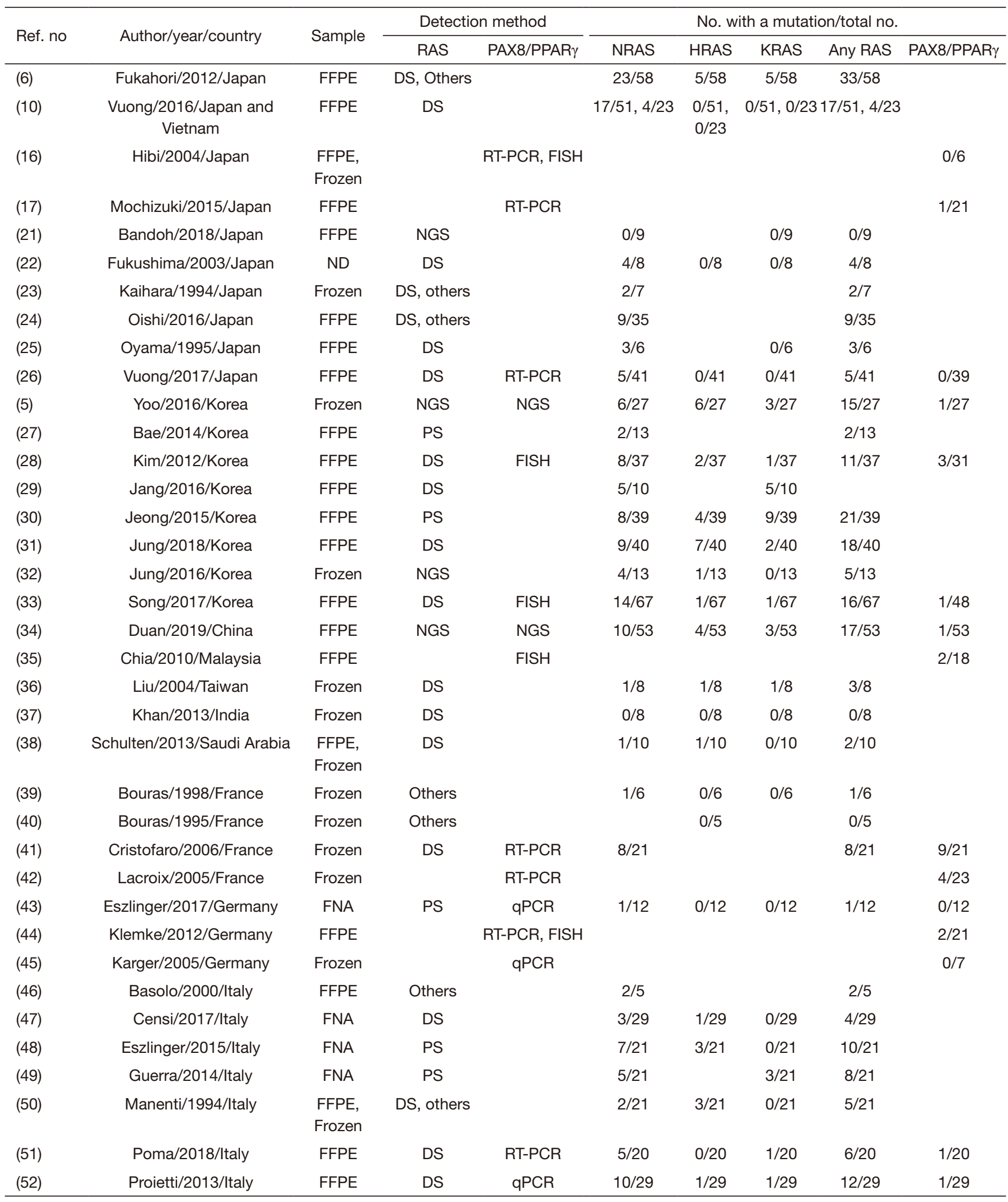

Table 1 (continued) 
Table 1 (continued)

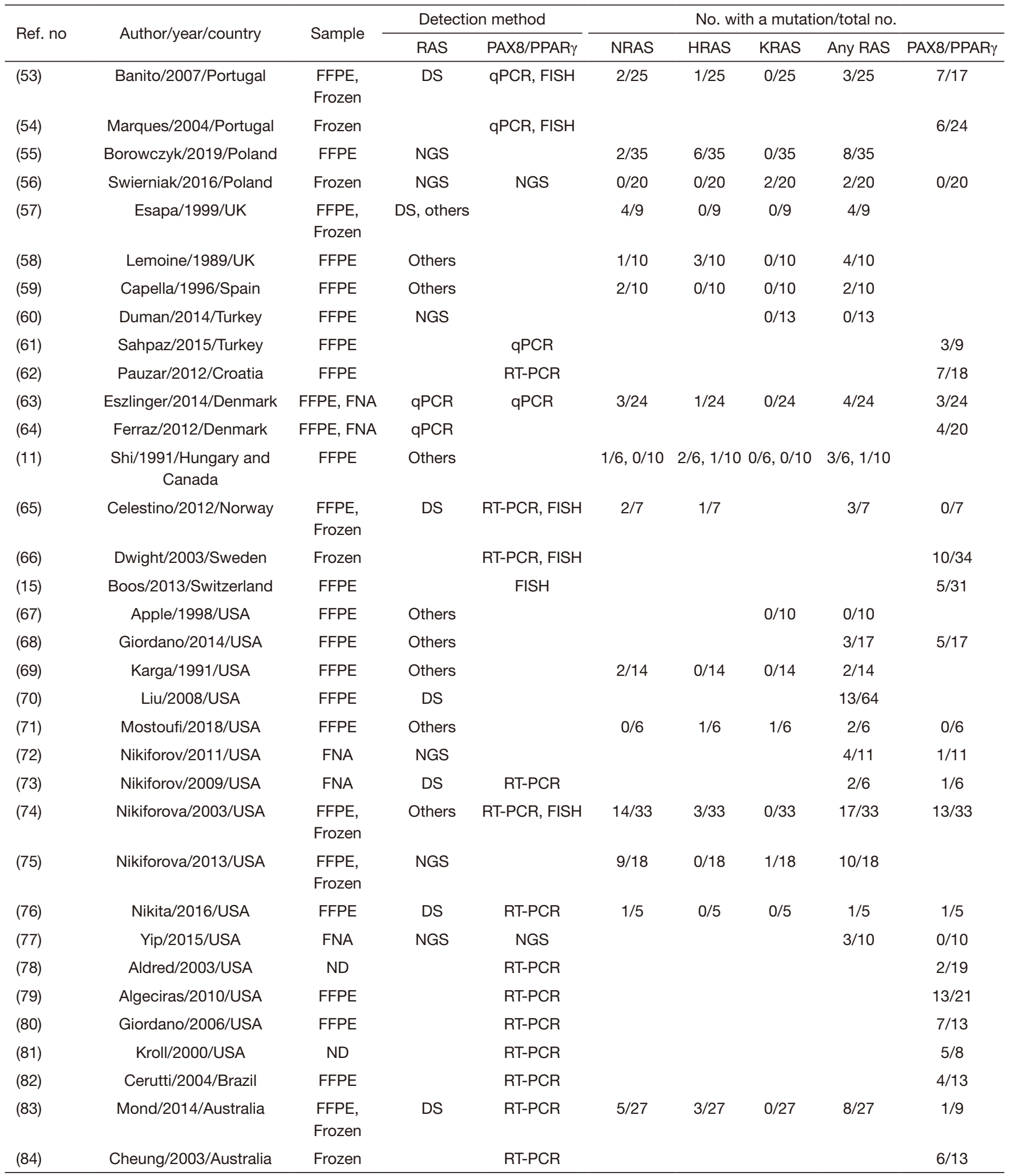

FFPE, formalin-fixed paraffin-embedded; FNA, fine needle aspiration; NGS, next generation sequencing; DS, direct sequencing; PS, pyrosequencing; RT-PCR, reverse transcription PCR; qPCR, quantitative PCR; FISH, fluorescence in situ hybridization. 
Table 2 Frequency of $R A S$ mutations and $P A X 8 / P P A R \gamma$ rearrangement in FTC patients by country

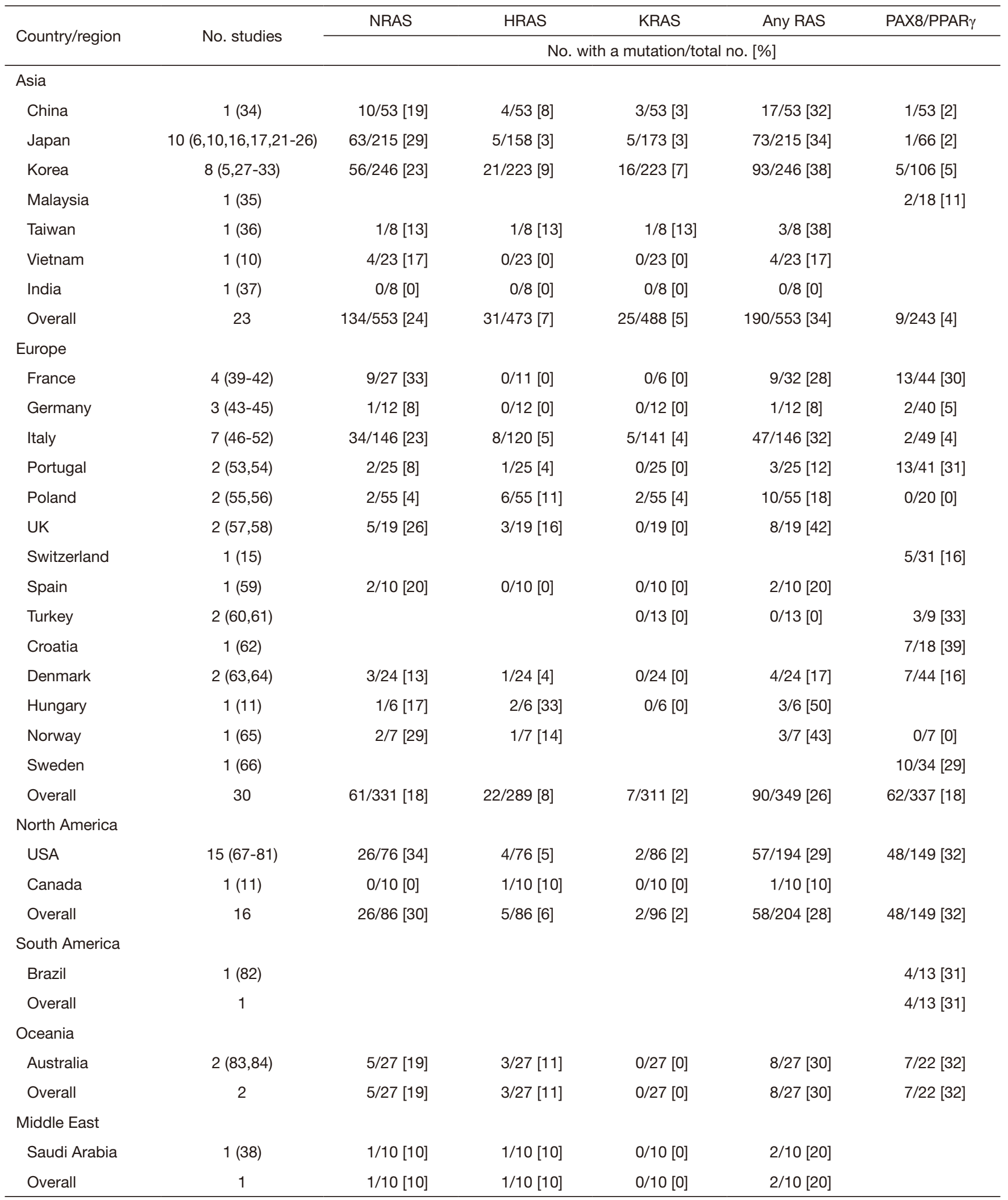

FTC, follicular thyroid carcinoma. 


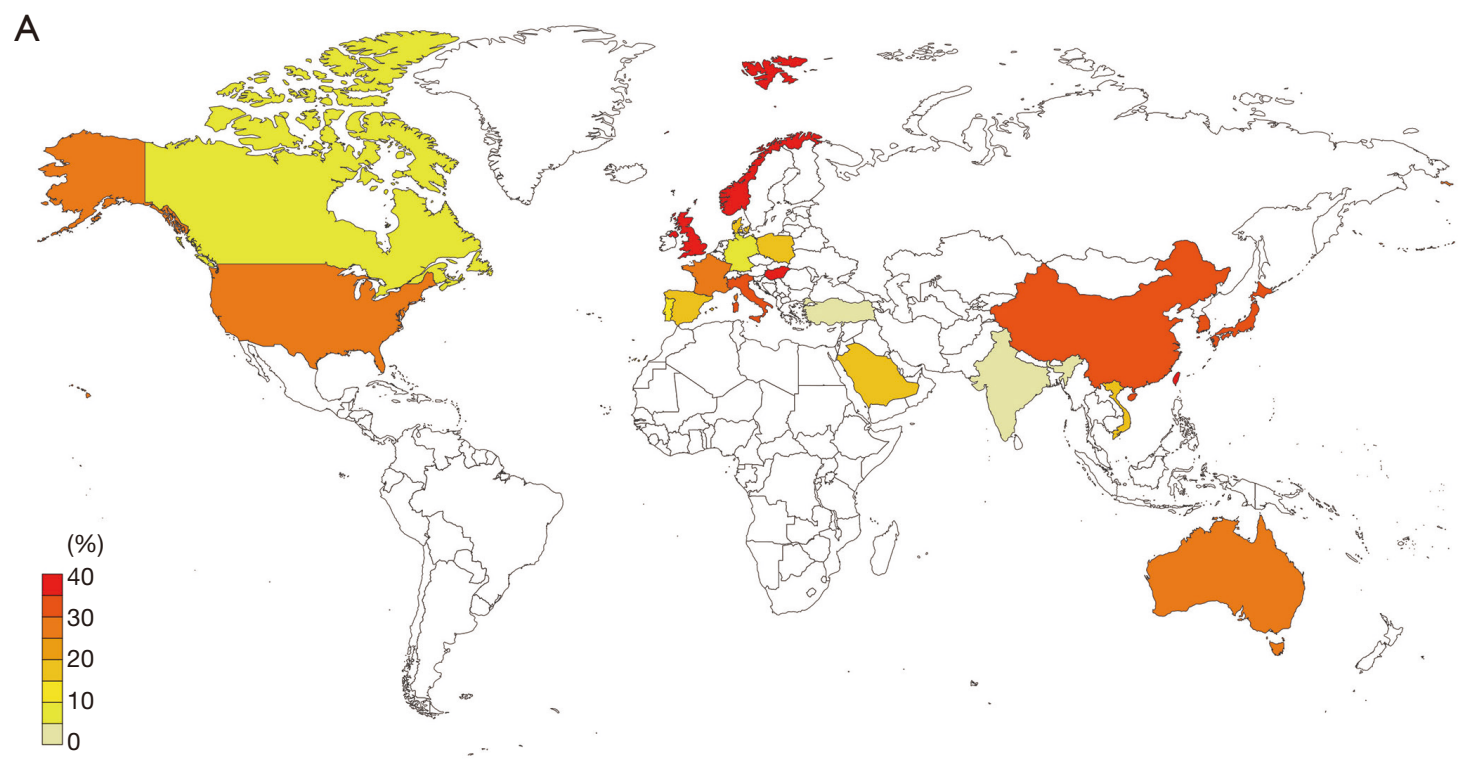

B

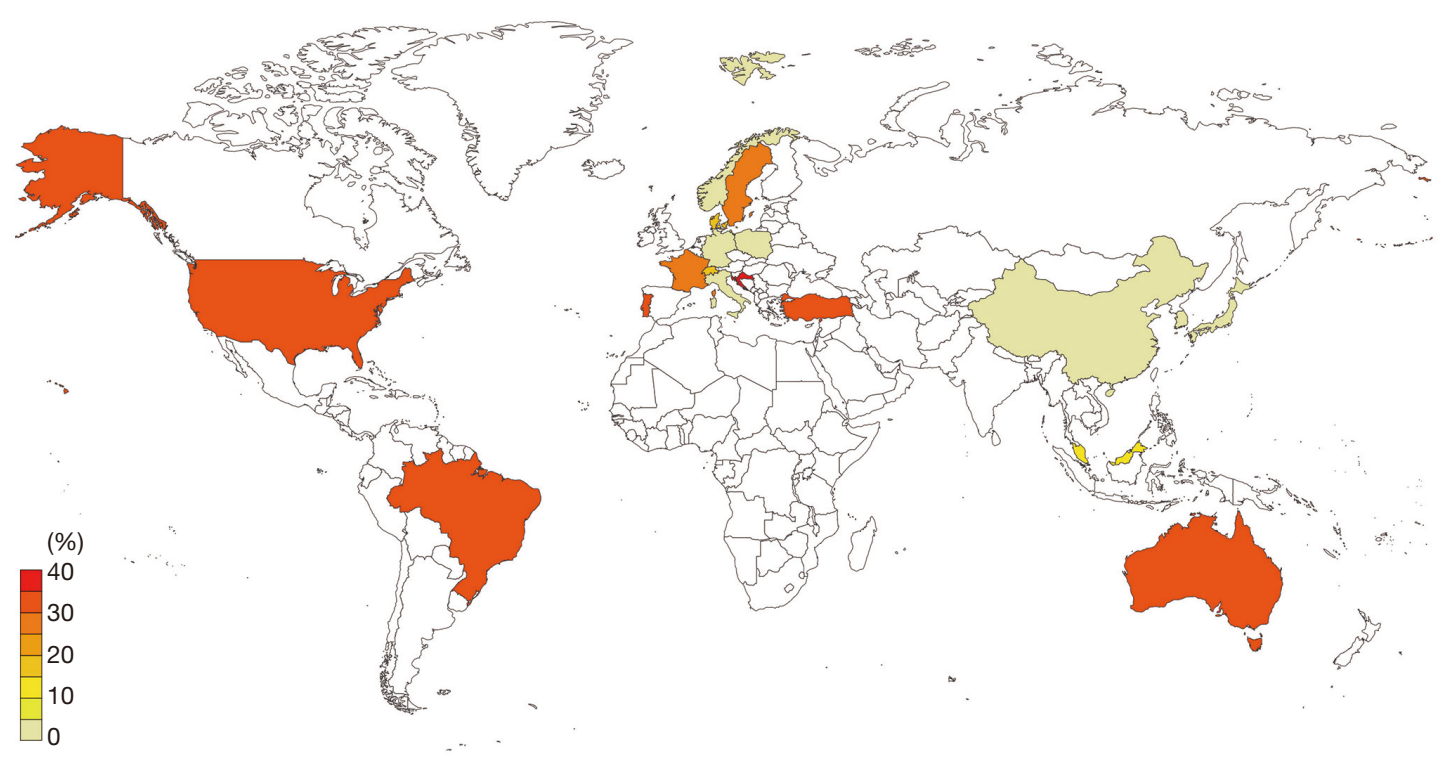

Figure 2 Global map of $R A S$ mutation (A) and PAX8/PPAR $\gamma$ rearrangement (B) in FTC patients. Countries where the data are unavailable are shown in white. FTC, follicular thyroid carcinoma.

had much lower frequencies. In North America, RAS mutation was relatively high (28\%). Although the frequency of NRAS and HRAS mutation was not different between Asian and European countries (24\% vs. 21\%, $\mathrm{P}=0.22$ and $7 \%$ vs. $7 \%, \mathrm{P}=0.71$, respectively), Asian countries had a slightly higher KRAS mutation frequency than Western countries
( $5 \%$ vs. $2 \%, \mathrm{P}=0.016$ ), and as a whole, the frequency of $R A S$ mutation in Asian countries was statistically higher than Western countries (34\% vs. 27\%, $\mathrm{P}=0.006$ ) (Table 3).

We thought that differences in the studies' detection methods might influence the reported RAS mutation frequencies. Therefore, we performed a subgroup analysis 
Table 3 RAS mutation and $P A X 8 / P P A R \gamma$ rearrangement frequency in Western and Asian countries

\begin{tabular}{lccc}
\hline \multirow{2}{*}{ Genetic alterations } & \multicolumn{2}{c}{ No. with mutation/total no. [\%] } & \multirow{2}{*}{ P value } \\
\cline { 2 - 3 } & Western countries & Asian countries & 0.22 \\
NRAS & $87 / 417[21]$ & $134 / 553[24]$ & 0.71 \\
HRAS & $27 / 375[7]$ & $31 / 473[7]$ & $0.016^{*}$ \\
KRAS & $9 / 427[2]$ & $25 / 488[5]$ & $0.006^{*}$ \\
Any RAS & $148 / 553[27]$ & $190 / 553[34]$ & $<0.001^{*}$ \\
PAX8/PPAR $\gamma$ & $110 / 486[23]$ & $9 / 243[4]$ & $<$.
\end{tabular}

Western countries include Europe and North American countries. * $\mathrm{P}$ value $<0.05$.

Table 4 Subgroup comparison of $R A S$ mutation frequency between Western and Asian countries

\begin{tabular}{lccc}
\hline \multirow{2}{*}{ Genetic alterations } & \multicolumn{1}{c}{ No. with mutation/total no. [\%] } & \multirow{2}{*}{ P value } \\
\cline { 2 - 3 } & Western countries & Asian countries & 0.93 \\
NRAS & $31 / 136[23]$ & $76 / 328[23]$ & 0.84 \\
HRAS & $4 / 115[3]$ & $11 / 283[4]$ & $10 / 293[3]$ \\
KRAS & $2 / 108[2]$ & $92 / 328[28]$ & 0.41 \\
Any RAS & $52 / 206[25]$ & 0.47 & \\
\hline
\end{tabular}

Western countries include Europe and North American countries.

incorporating studies using the direct sequencing method which is a gold standard for mutation detection and is the most prevalent method in our collection of studies. We found 21 studies with 534 FTC patients and divided them into Asian and Western countries. In the subgroup analysis, there was no statistical difference in $R A S$ mutation frequency between Asian and Western countries (28\% vs. $25 \%, \mathrm{P}=0.47$ ) (Table 4).

\section{PAX8/PPARy rearrangement in FTC patients by geographic region}

There were 39 articles with 764 FTC patients available for calculating the frequency of $P A X 8 / P P A R \gamma$ rearrangement. These included 8 studies from Asia (5,16,17,26,28,33-35), 17 studies from Europe (15,41-45,51-54,56,61-66), 11 studies from North America (68,71-74,76-81), 1 study from South America (82), and 2 studies from Oceania $(83,84)$. Table 2 and Figure $2 B$ show the frequencies of PAX8/PPAR $\gamma$ rearrangement. In Asian countries, the frequency of $P A X 8 /$ $P P A R \gamma$ rearrangement is low, ranging from $2 \%$ to $11 \%$. In North America, (all studies were from USA) the frequency was high (32\%). On the other hand, European countries had a variety of frequencies among countries. Germany, Italy, Poland and Norway had relatively low frequencies, less than 5\%, but France, Portugal and Croatia had greater than $30 \%$ frequency. As a whole, Western countries had a higher prevalence of $P A X 8 / P P A R \gamma$ rearrangement than Asian countries (23\% vs. 4\%, $\mathrm{P}<0.001)$ (Table 3).

\section{Discussion}

In our systematic review, we studied the geographical distribution of two representative genetic alterations in FTC and highlighted the similarities and differences between Asian and Western countries. Our study included all available published articles creating a comprehensive worldwide review focusing on the frequency of genetic alterations in FTC. Our results showed that RAS mutation in Asia is significantly more prevalent than in Western countries, although the difference disappeared in our subgroup analysis that only incorporating studies using direct sequencing method. We also showed that the incidence of PAX8/PPAR $\gamma$ rearrangement in the West was much higher than that found in Asia.

Our literature review showed that the reported 
frequencies of $R A S$ mutation and $P A X 8 / P P A R \gamma$ rearrangement in FTC vary widely, with $R A S$ mutation ranging from 0 to $57 \%$ and $P A X 8 / P P A R \gamma$ rearrangement ranging from 0 to $62 \%$. There are several hypotheses as to why there is such variation, and the method of detecting these mutations might especially influence the data collected on mutational frequency in these studies (9). Vasko et al. reported that direct sequencing detected RAS mutation less frequently than other methods because direct sequencing is unable to detect small numbers of mutated alleles in samples (85).

Our study includes various kinds of detection methods for $R A S$ mutation including direct sequencing, realtime quantitative PCR, allele specific PCR, allele-specific oligonucleotide hybridization (ASO), next generation sequencing (NGS), pyrosequencing, PCR-restriction fragment length polymorphism (RFLP), PCR-primer introduced restriction with enrichment for mutant alleles (PIREMA), multiplex PCR and liquid bead array assay. In our first analysis of the data, we did not consider the methodological differences between studies, and we found that differences in $R A S$ mutation frequency was consistent with a previous report (8). However, our subsequent subgroup analysis that was limited to studies using the direct sequencing method resulted in no statistical difference in $R A S$ mutation incidence between Asian and Western countries. This result implies that the difference between Asian and Western countries in $R A S$ mutation frequency does not exist or is lower than previously thought. Western countries tend to use more varied types of methodology for detecting mutations than do Asian countries. Direct sequencing was the method used in 52\% (10/19) of the studies from Asian countries but only $34 \%$ (9/26) of the studies from Western countries (Table 1). Detection methodology other than direct sequencing might decrease the apparent mutation frequency of $R A S$ mutation in Western countries. In contrast to RAS mutation, the detection method of PAX8/ $P P A R \gamma$ rearrangement is generally limited; almost all the studies used either reverse-transcription PCR (RT-PCR) or fluorescence in situ hybridization (FISH). Dwight et al. (66) reported slightly higher detection rates with FISH while Klemke et al. (44) reported that RT-PCR could detect $P A X 8 / P P A R \gamma$ rearrangement better than FISH. There was not a large difference between RT-PCR and FISH for detecting PAX8/PPAR $\gamma$ rearrangement, although there were several discrepant results. Even though studies from Asian countries adopted both the FISH and RT-PCR methods, the incidence of $P A X 8 / P P A R \gamma$ rearrangement is consistently low, ranging from 0 to $10 \%$. Therefore, it seems that factors other than detection methodology must account for the difference between Asian and Western countries in the incidence of $P A X 8 / P P A R \gamma$ rearrangement in FTC.

There is a discussion as to the relationship between iodine intake and thyroid cancer. Iodine intake is considered a factor in the occurrence of thyroid cancers and also the manner of tumorigenesis itself. The association between a high BRAF mutation ratio in PTC and a high iodine intake has been investigated and involves some controversy: Guan et al. (86) reported that a high iodine intake increased the BRAF mutation in PTC in the Chinese population, whereas other studies showed no association between iodine intake and BRAF mutation in PTC $(10,87)$. In FTC, the association between $R A S$ mutation and iodine intake is also disputed. Some authors concluded that there was no association between the amount of iodine ingested and $R A S$ mutation in FTC $(10,88)$ while others reported a tendency for higher rates of RAS mutation with low iodine intake (11). At present, to the best of our knowledge, there are no reports that examined the association between PAX8/PPAR $\gamma$ rearrangement and iodine intake. The studies reporting on the frequency of PAX8/PPAR $\gamma$ in Asia are mainly from Japan and Korea where the iodine intake is high. Therefore, it is possible that the high incidence of PAX8/PPAR $\gamma$ rearrangement in this region is due to the large amount of iodine ingested. However, iodine intake alone cannot explain the wide range of frequencies among Western countries where most populations have average iodine intakes (89). Iodine intake does not appear to be a definitive factor for the incidence of $P A X 8 / P P A R \gamma$ rearrangement.

It is well documented that radiation exposure can induce thyroid cancer. The main risk factors for the development of thyroid cancer are the radiation dose and the age at exposure (90). Radiation exposure is also known to affect the mechanism of carcinogenesis of thyroid cancer by causing a specific type of genetic rearrangement (91). Specific fusion genes are associated with a particular histologic type of PTC. The solid variant of PTC often harbors RET/PTC3 rearrangements while RET/PTC1 rearrangements are associated with the classical type of PTC (92). The occurrence of PAX8/PPAR $\gamma$ rearrangement is also reported in radiation-induced PTCs (93). However, information on the association between genetic alterations in FTC and radiation exposure are limited mainly due to the low incidence of radiation-induced FTCs. Nikiforova et al. reported that radiation-induced FTC had higher rates 
of $P A X 8 / P P A R \gamma$ rearrangement $(3 / 3,100 \%)$, although the non-radiation-induced counterparts also had a high incidence of the rearrangement (5/12, 42\%) (18). Radiation exposure might increase the frequency of PAX8/PPAR $\gamma$ rearrangement in FTC, but the incidence of non-radiationinduced FTC in the USA is still high compared to Asian countries. We believe that radiation exposure does not explain the difference in PAX8/PPAR $\gamma$ rearrangement frequency in FTC between Asia and the West. Further studies from a novel point of view would be needed to explain this regional difference.

There are several limitations in our study. First, most of the studies we included are retrospective, which might cause some selection bias. Second, heterogeneity in sample preparation (FFPE $v s$. frozen tissue) might affect the included studies' results. In addition, we could not completely exclude the influence that detection methods might have had in finding the genetic mutations, although we performed a subgroup analysis to account for this. The mutation detection rates of the direct sequencing method might be affected by the institution and the technology available during the era the samples were tested. To overcome this limitation, we would need a large prospective study using consistent detection and sample preparation methods. Apart from the technical point of view, we must consider the influence of observer variation in the diagnosis. Follicular thyroid lesions with the fibrous capsule which include adenomatous goiter, follicular variant of PTC, FA, and FTC, often raise difficulties and discrepancy in diagnosis. Hirokawa et al. showed the difference in diagnostic criteria of these lesions between Japanese and American pathologists (94). Franc et al. reported the low diagnostic reproducibility of minimally invasive FTC (95). Generally, PAX8/PPAR $\gamma$ rearrangement and $R A S$ mutation frequency in FTC is higher than FA $(36 \%$ vs. $11 \%$ and $40 \%$ vs. $26 \%$, respectively) $(9,12)$. Therefore, potential histological heterogeneity of previously reported FTC cases might influence our result. Finally, we must note that prevalence of genetic events might depend on the actual prevalence of the cancer in the population. Currently, information is limited about the underlying factors that can cause FTC or induce the specific genetic alterations. A certain unknown factor in the region may contribute to the tumorigenesis of FTC and thereby increase the frequency of FTC with a specific genetic alteration. Uncovering all the factors that contribute to tumorigenesis in FTC would provide a better understanding of FTC patients' genetic background around the world.
In conclusion, our study highlights differences and similarities in the genetic backgrounds of Asian and Western countries to create a global map of $R A S$ mutation and $P A X 8 / P P A R \gamma$ rearrangement. We further shed light on the lack of substantial data of genetic alteration in FTC within certain regions. Understanding the genetic information surrounding ethnical differences should improve the practice of clinical medicine in the future.

\section{Acknowledgments}

We wish to thank Pam Zaber, DVM of Editdoc English Editing for her help with English editing of this Journal article.

Funding: JSPS KAKENHI (Grants-in-Aid for Scientific Research) supported this work, Grant Number 19K16583.

\section{Footnote}

Provenance and Peer Review: This article was commissioned by the Guest Editor (Kennichi Kakudo) for the series "Asian and Western Practice in Thyroid Pathology: Similarities and Differences" published in Gland Surgery. The article was sent for external peer review organized by the Guest Editor and the editorial office.

Reporting Checklist: The authors have completed the PRISMA reporting checklist. Available at http://dx.doi. org/10.21037/gs-20-356

Conflicts of Interest: All authors have completed the ICMJE uniform disclosure form (available at http:// dx.doi.org/10.21037/gs-20-356). The series "Asian and Western Practice in Thyroid Pathology: Similarities and Differences" was commissioned by the editorial office without any funding or sponsorship. To reports grants from JSPS, during the conduct of the study. The authors have no other conflicts of interest to declare.

Ethical Statement: The authors are accountable for all aspects of the work in ensuring that questions related to the accuracy or integrity of any part of the work are appropriately investigated and resolved.

Open Access Statement: This is an Open Access article distributed in accordance with the Creative Commons Attribution-NonCommercial-NoDerivs 4.0 International License (CC BY-NC-ND 4.0), which permits the non- 
commercial replication and distribution of the article with the strict proviso that no changes or edits are made and the original work is properly cited (including links to both the formal publication through the relevant DOI and the license). See: https://creativecommons.org/licenses/by-nc-nd/4.0/.

\section{References}

1. Bray F, Ferlay J, Soerjomataram I, et al. Global cancer statistics 2018: GLOBOCAN estimates of incidence and mortality worldwide for 36 cancers in 185 countries. CA Cancer J Clin 2018;68:394-424.

2. Kondo T, Ezzat S, Asa SL. Pathogenetic mechanisms in thyroid follicular-cell neoplasia. Nat Rev Cancer 2006;6:292-306.

3. Fagin JA, Wells SA, Jr. Biologic and Clinical Perspectives on Thyroid Cancer. N Engl J Med 2016;375:2307.

4. Cabanillas ME, McFadden DG, Durante C. Thyroid cancer. Lancet 2016;388:2783-95.

5. Yoo SK, Lee S, Kim SJ, et al. Comprehensive Analysis of the Transcriptional and Mutational Landscape of Follicular and Papillary Thyroid Cancers. PLoS Genet 2016;12:e1006239.

6. Fukahori M, Yoshida A, Hayashi H, et al. The associations between RAS mutations and clinical characteristics in follicular thyroid tumors: new insights from a single center and a large patient cohort. Thyroid 2012;22:683-9.

7. Jang EK, Song DE, Sim SY, et al. NRAS codon 61 mutation is associated with distant metastasis in patients with follicular thyroid carcinoma. Thyroid 2014;24:1275-81.

8. Song YS, Lim JA, Park YJ. Mutation Profile of WellDifferentiated Thyroid Cancer in Asians. Endocrinol Metab (Seoul) 2015;30:252-62.

9. Howell GM, Hodak SP, Yip L. RAS mutations in thyroid cancer. Oncologist 2013;18:926-32.

10. Vuong HG, Kondo T, Oishi N, et al. Genetic alterations of differentiated thyroid carcinoma in iodine-rich and iodine-deficient countries. Cancer Med 2016;5:1883-9.

11. Shi YF, Zou MJ, Schmidt H, et al. High rates of ras codon 61 mutation in thyroid tumors in an iodide-deficient area. Cancer Res 1991;51:2690-3.

12. Placzkowski KA, Reddi HV, Grebe SK, et al. The Role of the PAX8/PPARgamma Fusion Oncogene in Thyroid Cancer. PPAR Res 2008;2008:672829.

13. Raman P, Koenig RJ. Pax-8-PPAR-gamma fusion protein in thyroid carcinoma. Nat Rev Endocrinol 2014;10:616-23.
14. Daniels GH. Follicular Thyroid Carcinoma: A Perspective. Thyroid 2018;28:1229-42.

15. Boos LA, Dettmer M, Schmitt A, et al. Diagnostic and prognostic implications of the PAX8-PPARgamma translocation in thyroid carcinomas-a TMA-based study of 226 cases. Histopathology 2013;63:234-41.

16. Hibi Y, Nagaya T, Kambe F, et al. Is thyroid follicular cancer in Japanese caused by a specific $\mathrm{t}(2 ; 3)(\mathrm{q} 13 ; \mathrm{p} 25)$ translocation generating Pax8-PPAR gamma fusion mRNA? Endocr J 2004;51:361-6.

17. Mochizuki K, Kondo T, Oishi N, et al. Low frequency of PAX8-PPARgamma rearrangement in follicular thyroid carcinomas in Japanese patients. Pathol Int 2015;65:250-3.

18. Nikiforova MN, Biddinger PW, Caudill CM, et al. PAX8PPARgamma rearrangement in thyroid tumors: RT-PCR and immunohistochemical analyses. Am J Surg Pathol 2002;26:1016-23.

19. Moher D, Liberati A, Tetzlaff J, et al. Preferred reporting items for systematic reviews and meta-analyses: the PRISMA statement. PLoS Med 2009;6:e1000097.

20. Kakudo K, Bychkov A, Bai Y, et al. The new 4th edition World Health Organization classification for thyroid tumors, Asian perspectives. Pathol Int 2018;68:641-64.

21. Bandoh N, Akahane T, Goto T, et al. Targeted nextgeneration sequencing of cancer-related genes in thyroid carcinoma: A single institution's experience. Oncol Lett 2018;16:7278-86.

22. Fukushima T, Suzuki S, Mashiko M, et al. BRAF mutations in papillary carcinomas of the thyroid. Oncogene 2003;22:6455-7.

23. Kaihara M, Taniyama M, Tadatomo J, et al. Specific PCR amplification for N-ras mutations in neoplastic thyroid diseases. Endocr J 1994;41:301-8.

24. Oishi N, Kondo T, Vuong HG, et al. Immunohistochemical detection of NRAS(Q61R) protein in follicular-patterned thyroid tumors. Hum Pathol 2016;53:51-7.

25. Oyama T, Suzuki T, Hara F, et al. N-ras mutation of thyroid tumor with special reference to the follicular type. Pathol Int 1995;45:45-50.

26. Vuong HG, Kondo T, Oishi N, et al. Paediatric follicular thyroid carcinoma - indolent cancer with low prevalence of RAS mutations and absence of PAX8-PPARG fusion in a Japanese population. Histopathology 2017;71:760-8.

27. Bae JS, Choi SK, Jeon S, et al. Impact of NRAS Mutations on the Diagnosis of Follicular Neoplasm of the Thyroid. Int J Endocrinol 2014;2014:289834.

28. Kim HJ, Jang HW, Sohn SY, et al. Frequency of 
RAS Mutations and PAX8/PPAR $\gamma$ Rearrangement in Follicular Thyroid Tumors in Korea. Endocrinol Metab 2012;27:45-53.

29. Jang EK, Kim WG, Kim EY, et al. Usefulness of NRAS codon 61 mutation analysis and core needle biopsy for the diagnosis of thyroid nodules previously diagnosed as atypia of undetermined significance. Endocrine 2016;52:305-12.

30. Jeong SH, Hong HS, Kwak JJ, et al. Analysis of RAS mutation and PAX8/PPARgamma rearrangements in follicular-derived thyroid neoplasms in a Korean population: frequency and ultrasound findings. J Endocrinol Invest 2015;38:849-57.

31. Jung CK, Kim Y, Jeon S, et al. Clinical utility of EZH1 mutations in the diagnosis A Check for of follicular-patterned thyroid tumors. Human Pathology 2018;81:9-17.

32. Jung SH, Kim MS, Jung CK, et al. Mutational burdens and evolutionary ages of thyroid follicular adenoma are comparable to those of follicular carcinoma. Oncotarget 2016;7:69638-48.

33. Song YS, Lim JA, Min HS, et al. Changes in the clinicopathological characteristics and genetic alterations of follicular thyroid cancer. Eur J Endocrinol 2017;177:465-73.

34. Duan H, Liu X, Ren X, et al. Mutation profiles of follicular thyroid tumors by targeted sequencing. Diagn Pathol 2019;14:39.

35. Chia WK, Sharifah NA, Reena RM, et al. Fluorescence in situ hybridization analysis using PAX8- and PPARGspecific probes reveals the presence of PAX8-PPARG translocation and 3p25 aneusomy in follicular thyroid neoplasms. Cancer Genet Cytogenet 2010;196:7-13.

36. Liu RT, Hou CY, You HL, et al. Selective occurrence of ras mutations in benign and malignant thyroid follicular neoplasms in Taiwan. Thyroid 2004;14:616-21.

37. Khan MS, Pandith AA, Ul Hussain M, et al. Lack of mutational events of RAS genes in sporadic thyroid cancer but high risk associated with HRAS T81C single nucleotide polymorphism (case-control study). Tumour Biol 2013;34:521-9.

38. Schulten HJ, Salama S, Al-Ahmadi A, et al. Comprehensive survey of HRAS, KRAS, and NRAS mutations in proliferative thyroid lesions from an ethnically diverse population. Anticancer Res 2013;33:4779-84.

39. Bouras M, Bertholon J, Dutrieux-Berger N, et al. Variability of Ha-ras (codon 12) proto-oncogene mutations in diverse thyroid cancers. Eur J Endocrinol 1998;139:209-16.
40. Bouras M, Parvaz P, Berger N, et al. Ha-ras oncogene (codon 12) mutation in thyroid carcinogenesis: analysis of 60 benign and malignant thyroid tumors. Ann Biol Clin (Paris) 1995;53:549-55.

41. Di Cristofaro J, Silvy M, Lanteaume A, et al. Expression of tpo mRNA in thyroid tumors: quantitative PCR analysis and correlation with alterations of ret, Braf, ras and pax8 genes. Endocr Relat Cancer 2006;13:485-95.

42. Lacroix L, Lazar V, Michiels S, et al. Follicular thyroid tumors with the PAX8-PPARgamma1 rearrangement display characteristic genetic alterations. Am J Pathol 2005;167:223-31.

43. Eszlinger M, Bohme K, Ullmann M, et al. Evaluation of a Two-Year Routine Application of Molecular Testing of Thyroid Fine-Needle Aspirations Using a Seven-Gene Panel in a Primary Referral Setting in Germany. Thyroid 2017;27:402-11.

44. Klemke M, Drieschner N, Belge G, et al. Detection of PAX8-PPARG fusion transcripts in archival thyroid carcinoma samples by conventional RT-PCR. Genes Chromosomes Cancer 2012;51:402-8.

45. Karger S, Berger K, Eszlinger M, et al. Evaluation of peroxisome proliferator-activated receptor-gamma expression in benign and malignant thyroid pathologies. Thyroid 2005;15:997-1003.

46. Basolo F, Pisaturo F, Pollina LE, et al. N-ras mutation in poorly differentiated thyroid carcinomas: correlation with bone metastases and inverse correlation to thyroglobulin expression. Thyroid 2000;10:19-23.

47. Censi S, Cavedon E, Bertazza L, et al. Frequency and Significance of Ras, Tert Promoter, and Braf Mutations in Cytologically Indeterminate Thyroid Nodules: A Monocentric Case Series at a Tertiary-Level Endocrinology Unit. Front Endocrinol (Lausanne) 2017;8:273.

48. Eszlinger M, Piana S, Moll A, et al. Molecular testing of thyroid fine-needle aspirations improves presurgical diagnosis and supports the histologic identification of minimally invasive follicular thyroid carcinomas. Thyroid 2015;25:401-9.

49. Guerra A, Carrano M, Angrisani E, et al. Detection of RAS mutation by pyrosequencing in thyroid cytology samples. Int J Surg 2014;12 Suppl 1:S91-4.

50. Manenti G, Pilotti S, Re FC, et al. Selective activation of ras oncogenes in follicular and undifferentiated thyroid carcinomas. Eur J Cancer 1994;30a:987-93.

51. Poma AM, Giannini R, Piaggi P, et al. A six-gene panel to label follicular adenoma, low- and high-risk follicular 
thyroid carcinoma. Endocr Connect 2018;7:124-32.

52. Proietti A, Sartori C, Borrelli N, et al. Follicular-derived neoplasms: morphometric and genetic differences. J Endocrinol Invest 2013;36:1055-61.

53. Banito A, Pinto AE, Espadinha C, et al. Aneuploidy and RAS mutations are mutually exclusive events in the development of well-differentiated thyroid follicular tumours. Clin Endocrinol (Oxf) 2007;67:706-11.

54. Marques AR, Espadinha C, Frias MJ, et al. Underexpression of peroxisome proliferator-activated receptor (PPAR)gamma in PAX8/PPARgamma-negative thyroid tumours. Br J Cancer 2004;91:732-8.

55. Borowczyk M, Szczepanek-Parulska E, Debicki S, et al. Differences in Mutational Profile between Follicular Thyroid Carcinoma and Follicular Thyroid Adenoma Identified Using Next Generation Sequencing. Int J Mol Sci 2019;20:3126.

56. Swierniak M, Pfeifer A, Stokowy T, et al. Somatic mutation profiling of follicular thyroid cancer by next generation sequencing. Mol Cell Endocrinol 2016;433:130-7.

57. Esapa CT, Johnson SJ, Kendall-Taylor P, et al. Prevalence of Ras mutations in thyroid neoplasia. Clin Endocrinol (Oxf) 1999;50:529-35.

58. Lemoine NR, Mayall ES, Wyllie FS, et al. High frequency of ras oncogene activation in all stages of human thyroid tumorigenesis. Oncogene 1989;4:159-64.

59. Capella G, Matias-Guiu X, Ampudia X, et al. Ras oncogene mutations in thyroid tumors: polymerase chain reaction-restriction-fragment-length polymorphism analysis from paraffin-embedded tissues. Diagn Mol Pathol 1996;5:45-52.

60. Duman BB, Kara OI, Uguz A, et al. Evaluation of PTEN, PI3K, MTOR, and KRAS expression and their clinical and prognostic relevance to differentiated thyroid carcinoma. Contemp Oncol (Pozn) 2014;18:234-40.

61. Sahpaz A, Onal B, Yesilyurt A, et al. BRAF(V600E) Mutation, RET/PTC1 and PAX8-PPAR Gamma Rearrangements in Follicular Epithelium Derived Thyroid Lesions - Institutional Experience and Literature Review. Balkan Med J 2015;32:156-66.

62. Pauzar B, Karner I, Glavas-Obrovac L, et al. PAX8PPARgamma oncogene in follicular thyroid tumors: RTPCR and immunohistochemical analyses. Coll Antropol 2012;36 Suppl 2:79-82.

63. Eszlinger M, Krogdahl A, Munz S, et al. Impact of molecular screening for point mutations and rearrangements in routine air-dried fine-needle aspiration samples of thyroid nodules. Thyroid 2014;24:305-13.
64. Ferraz C, Rehfeld C, Krogdahl A, et al. Detection of PAX8/PPARG and RET/PTC rearrangements is feasible in routine air-dried fine needle aspiration smears. Thyroid 2012;22:1025-30.

65. Celestino R, Sigstad E, Lovf M, et al. Survey of 548 oncogenic fusion transcripts in thyroid tumors supports the importance of the already established thyroid fusions genes. Genes Chromosomes Cancer 2012;51:1154-64.

66. Dwight T, Thoppe SR, Foukakis T, et al. Involvement of the PAX8/peroxisome proliferator-activated receptor gamma rearrangement in follicular thyroid tumors. J Clin Endocrinol Metab 2003;88:4440-5.

67. Apple SK, Alzona MC, Jahromi SA, et al. Can Different Thyroid Tumor Types Be Distinguished by Polymerase Chain Reaction-Based K-ras Mutation Detection? Mol Diagn 1998;3:143-7.

68. Giordano TJ, Beaudenon-Huibregtse S, Shinde R, et al. Molecular testing for oncogenic gene mutations in thyroid lesions: a case-control validation study in 413 postsurgical specimens. Hum Pathol 2014;45:1339-47.

69. Karga H, Lee JK, Vickery AL, Jr., et al. Ras oncogene mutations in benign and malignant thyroid neoplasms. J Clin Endocrinol Metab 1991;73:832-6.

70. Liu Z, Hou P, Ji M, et al. Highly prevalent genetic alterations in receptor tyrosine kinases and phosphatidylinositol 3-kinase/akt and mitogen-activated protein kinase pathways in anaplastic and follicular thyroid cancers. J Clin Endocrinol Metab 2008;93:3106-16.

71. Mostoufi-Moab S, Labourier E, Sullivan L, et al. Molecular Testing for Oncogenic Gene Alterations in Pediatric Thyroid Lesions. Thyroid 2018;28:60-7.

72. Nikiforov YE, Ohori NP, Hodak SP, et al. Impact of mutational testing on the diagnosis and management of patients with cytologically indeterminate thyroid nodules: a prospective analysis of 1056 FNA samples. J Clin Endocrinol Metab 2011;96:3390-7.

73. Nikiforov YE, Steward DL, Robinson-Smith TM, et al. Molecular Testing for Mutations in Improving the FineNeedle Aspiration Diagnosis of Thyroid Nodules. J Clin Endocrinol Metab 2009;94:2092-8.

74. Nikiforova MN, Lynch RA, Biddinger PW, et al. RAS point mutations and PAX8-PPAR gamma rearrangement in thyroid tumors: evidence for distinct molecular pathways in thyroid follicular carcinoma. J Clin Endocrinol Metab 2003;88:2318-26.

75. Nikiforova MN, Wald AI, Roy S, et al. Targeted nextgeneration sequencing panel (ThyroSeq) for detection of mutations in thyroid cancer. J Clin Endocrinol Metab 
2013;98:E1852-60.

76. Nikita ME, Jiang W, Cheng SM, et al. Mutational Analysis in Pediatric Thyroid Cancer and Correlations with Age, Ethnicity, and Clinical Presentation. Thyroid 2016;26:227-34.

77. Yip L, Nikiforova MN, Yoo JY, et al. Tumor genotype determines phenotype and disease-related outcomes in thyroid cancer: a study of 1510 patients. Ann Surg 2015;262:519-25; discussion 24-5.

78. Aldred MA, Morrison C, Gimm O, et al. Peroxisome proliferator-activated receptor gamma is frequently downregulated in a diversity of sporadic nonmedullary thyroid carcinomas. Oncogene 2003;22:3412-6.

79. Algeciras-Schimnich A, Milosevic D, McIver B, et al. Evaluation of the PAX8/PPARG translocation in follicular thyroid cancer with a 4-color reverse-transcription PCR assay and automated high-resolution fragment analysis. Clin Chem 2010;56:391-8.

80. Giordano TJ, Au AY, Kuick R, et al. Delineation, functional validation, and bioinformatic evaluation of gene expression in thyroid follicular carcinomas with the PAX8PPARG translocation. Clin Cancer Res 2006;12:1983-93.

81. Kroll TG, Sarraf P, Pecciarini L, et al. PAX8-PPAR gamma 1 fusion in oncogene human thyroid carcinoma. Science 2000;289:1357-60.

82. Cerutti JM, Delcelo R, Amadei MJ, et al. A preoperative diagnostic test that distinguishes benign from malignant thyroid carcinoma based on gene expression. J Clin Invest 2004;113:1234-42.

83. Mond M, Alexiadis M, Fuller PJ, et al. Mutation profile of differentiated thyroid tumours in an Australian urban population. Intern Med J 2014;44:727-34.

84. Cheung L, Messina M, Gill A, et al. Detection of the PAX8-PPAR gamma fusion oncogene in both follicular thyroid carcinomas and adenomas. J Clin Endocrinol Metab 2003;88:354-7.

85. Vasko V, Ferrand M, Di Cristofaro J, et al. Specific pattern of RAS oncogene mutations in follicular thyroid tumors. J

Cite this article as: Odate T, Oishi N, Vuong HG, Mochizuki K, Kondo T. Genetic differences in follicular thyroid carcinoma between Asian and Western countries: a systematic review. Gland Surg 2020;9(5):1813-1826. doi: 10.21037/gs-20-356
Clin Endocrinol Metab 2003;88:2745-52.

86. Guan H, Ji M, Bao R, et al. Association of high iodine intake with the T1799A BRAF mutation in papillary thyroid cancer. J Clin Endocrinol Metab 2009;94:1612-7.

87. Frasca F, Nucera C, Pellegriti G, et al. BRAF(V600E) mutation and the biology of papillary thyroid cancer. Endocr Relat Cancer 2008;15:191-205.

88. Bartolone L, Vermiglio F, Finocchiaro MD, et al. Thyroid follicular oncogenesis in iodine-deficient and iodinesufficient areas: search for alterations of the ras, met and bFGF oncogenes and of the Rb anti-oncogene. J Endocrinol Invest 1998;21:680-7.

89. Iodine Global Network. Global scorecard of iodine nutrition in 2017 in the general population and in pregnant women (PW). Zurich, IGN: 2017.

90. Iglesias ML, Schmidt A, Ghuzlan AA, et al. Radiation exposure and thyroid cancer: a review. Arch Endocrinol Metab 2017;61:180-7.

91. Ricarte-Filho JC, Li S, Garcia-Rendueles ME, et al. Identification of kinase fusion oncogenes in postChernobyl radiation-induced thyroid cancers. J Clin Invest 2013;123:4935-44.

92. Nikiforov YE, Rowland JM, Bove KE, et al. Distinct pattern of ret oncogene rearrangements in morphological variants of radiation-induced and sporadic thyroid papillary carcinomas in children. Cancer Res 1997;57:1690-4.

93. Leeman-Neill RJ, Brenner AV, Little MP, et al. RET/PTC and PAX8/PPARgamma chromosomal rearrangements in post-Chernobyl thyroid cancer and their association with iodine-131 radiation dose and other characteristics. Cancer 2013;119:1792-9.

94. Hirokawa M, Carney JA, Goellner JR, et al. Observer variation of encapsulated follicular lesions of the thyroid gland. Am J Surg Pathol 2002;26:1508-14.

95. Franc B, de la Salmoniere P, Lange F, et al. Interobserver and intraobserver reproducibility in the histopathology of follicular thyroid carcinoma. Hum Pathol 2003;34:1092-100. 